\title{
A quANTAS MÃos SE ESCREVE A HISTÓRIA DA LITERATURA? A POLÍTICA DAS DIVERGÊNCIAS TEÓRICAS NA INDONÉSIA
}

Felipe Vale da Silva iD $\nabla$

Universidade Federal de Goiás

$\mathrm{P}$

or muito tempo contou-se a mesma história sobre as origens da literatura indonésia: “a literatura moderna indonésia nasceu por volta de 1920”. Subentende-se por tempos modernos o momento a partir do qual "indonésios começaram a expressar sentimentos e ideias basicamente distintos daqueles predominantes nas sociedades indígenas tradicionais”. ${ }^{1}$ Seguindo essa formulação, o orientalista holandês Andries Teeuw elencou um rol de artistas ligados à casa editorial Balai Pustaka, fundada em 1917, coroando-os como representantes de uma nova disposição criativa que ancorou a literatura indonésia, digamos, na literatura universal.

O diferencial desses novos escritores teria sido o ímpeto de formular uma identidade nacional do que era então chamado de Índias Orientais Neerlandesas - uma entidade constituída por centenas de ilhas que funcionavam desde o século XVII como colônias de exploração, diretamente administradas sob um regime de apartheid, não pela coroa holandesa, mas por uma empresa, a Companhia [unida] da Índias Orientais. ${ }^{2}$

1 Andries Teeuw, Modern Indonesian Literature, Dordrecht: Springer, 1967, p. 1. Todas as traduções são do articulista, salvo quando indicado.

2 Ou Vereenigde Oostindische Compagnie, a primeira sociedade anônima por ações (joint-stocks) da História. Em função da longa distância entre sua sede em Amsterdã e as colônias sul-asiáticas, logo seus acionistas ganharam enorme autonomia no território onde atuavam (a empresa, por exemplo, foi a única de que se tem notícia com 
Esse amontoado de particularidades acarretou um processo de nacionalização sui generis. O conceito de nação indonésia não derivou de uma unidade étnica - 300 etnias convivem dentro do perímetro do país -, tampouco de uma unidade linguística - o idioma oficial bahasa indonesia é um dentre 742 idiomas regionais reconhecidos, e precisou passar por uma ampla campanha de divulgação para se tornar língua franca. ${ }^{3}$ Tendo em vista essa complexidade, Teeuw argumenta que um despertar nacional da Indonésia teve de ocorrer na dependência da iniciativa de nativos educados na Europa, versados no idioma e nos valores do colonizador. Foi necessário o surgimento de Budi Utomo, "a primeira organização indonésia em termos ocidentais”, para que se executasse uma ruptura radical com o passado. ${ }^{4} \mathrm{O}$ Budi Utomo tem um título javanês de difícil tradução (podendo ser traduzido por algo como o nobre compromisso) e surgiu como um congresso de estudantes, jornalistas e educadores em maio de 1908 onde se discutiram formas de integração da população local educada à dinâmica administrativa das Î́ndias. Seu alvo, no início, não foi explicitamente político, embora a política tenha se tornado um desdobramento inevitável daquela mobilização inédita de nativos, que pela primeira vez se declaravam decididos a tomar seu destino em suas próprias mãos.

Em 1910, quando foi reconhecido pelo governo metropolitano, o grupo já contava com dez mil membros registrados em quarenta filiais regionais. ${ }^{5}$ Sua importância para aqueles que posteriormente idealizaram a independência nacional é inegável, qualquer que seja seu espectro político: a organização unia holandeses, eurásios (mestiços de europeus e de etnias

poderes de declarar guerra contra uma ou outra nação), o que fez da colonização holandesa um processo particularmente sanguinolento. Foi dissolvida em 1799 em função de má administração, sendo integrada à administração real desde então.

3 Por se tratar de uma língua simplificada, relativamente igualitária, o bahasa indonesia foi eleito como língua oficial, e não mais o complexo javanês (falado pela maioria dos locais durante a era colonial), ou mesmo a língua da metrópole (como ocorreu nas demais colônias europeias). Voltaremos a discutir a língua indonésia como língua literária eleita por uma comunidade de autores e leitores a partir de 1926.

4 Teeuw, Modern Indonesian Literature, p. 2.

5 Amry Vandenbosch, "Nationalism in Netherlands East India”, Pacific Affairs, v. 4, n. 12 (1931), p. 1058. 
autóctones) e nativos em prol de uma política e cultura próprias das Índias Orientais. Ideias nacionalistas foram logo acompanhadas pela necessidade da autogerência que eventualmente tiraria os holandeses do poder por meio da guerra de independência de 1945 a 1949. Mesmo em uma época posterior de divisão interna, o Budi Utomo serviu de catalisador para diversos outros grupos locais de nacionalistas, dentre os quais muitos se tornariam partidos políticos ativos até hoje. ${ }^{6}$ Ademais, seus membros produziram a literatura nativa da época, veiculando ideias e dilemas que se remetiam a uma Indonésia moderna, urbanizada. Mesmo os integrantes da orgulhosa aristocracia javanesa deixaram de usar seu idioma nativo para adotar o que então se chamava de bahasa melayu tinggi (“alto malaio”) como língua de comunicação social e expressão literária.

Teeuw não poderia prever as consequências futuras de sua ideia: é razoável dizer que a afirmação introdutória de seu compêndio Pokok dan Tokoh, de 1952, terminou por transformar um riquíssimo repertório de tradições malaias, papuásias, javanesas, maduresas, sundanesas etc. em uma categoria de literatura pré-moderna, como se fossem construções culturais de línguas mortas. ${ }^{7} \mathrm{O}$ fato de seu livro ter sido traduzido para o inglês (por ele mesmo) como Modern Indonesian Literature - um título de certa autoridade, a propósito, sobretudo em uma época em que não havia outras histórias da literatura indonésia disponíveis em inglês - certamente contribuiu para difundir suas ideias. No entanto, a existência atual e a influência das tradições orais de diversas culturas do país sobre a produção de teatro, poesia, cinema e ficção contemporâneas contam, por si mesmas, como uma refutação dos pressupostos de Teeuw: outras tradições além da modernista, de extração europeia, resistiram ao teste do tempo,

6 Kementerian Pendidikan dan Kebudayaan, Sejarah Indonesia, Jakarta: Kementerian Pendidikan dan Kebudayaan, 2014, pp. 140 et seq.

7 Adicionemos que essa divisão radical não foi obra exclusiva de A. Teeuw, mas também foi veiculada em obras de orientalistas desde o artigo de 1932 de Gerardus Willebrordus Joannes Drewes, Oud en Nieuw in de Hedendaagsche Indonesische Literatuur, Noodwijk: [s. n.], 1932. Discordou-se sobre o início de uma literatura devidamente indonésia, partindo-se sempre do pressuposto de que a presença holandesa foi essencial para seu advento. 
constituindo-se como legados culturais que inserem a Indonésia no mapa da ficção mundial por vias não oficiais. ${ }^{8}$

Como Ibnu Wahyudi mostrou, ${ }^{9}$ a seletividade de Teeuw não é só um motivo para desconfiarmos de seu rigor científico - afinal, como orientalista, ele só reconhece o valor artístico de produções de autores que estudaram na Europa e absorveram tendências da metrópole. Antes, há implicações mais sérias advindas da singela formulação “a literatura indonésia moderna nasceu por volta de 1920”: este foi e é, até hoje, o conceito impresso em material curricular utilizado tanto no ensino médio como em cursos universitários do sudeste asiático. Sob tal paradigma, milhões de alunos e alunas que se tornaram os acadêmicos da Indonésia independente assumiram uma determinada identidade cultural, segundo a qual seu povo só desenvolveu uma cultura literária apta a ser consumida atualmente por força do apadrinhamento holandês (isto é, pelo surgimento de uma geração crioula). O erro, de tanto ser repetido, adquiriu estatuto de lugar-comum. Consequentemente, há poucas pesquisas desenvolvidas nas universidades asiáticas sobre a literatura do baixo-malaio (bahasa melayu pasar, o idioma literário predominante entre 1850 e 1910) ou das populações sino-indonésias (por meio das quais, de fato, a literatura

8 Os exemplos são diversos. Como bem pontuou Cobina Asmara, “Tradisi Baru: A New Tradition of Indonesian Theatre”, Asia Theatre Journal, v. 12, n. 1 (1995), p. 165, "uma das qualidades mais duradouras das artes tradicionais indonésias é que elas não pertencem inteiramente ao passado, [mas] estão constantemente se atualizando para [dar conta de] cobrir questões da atualidade”. No caso do teatro de rua javanês contemporâneo, observa-se antes um diálogo com a tradição milenar do teatro de sombras medieval do que uma relação com Bertolt Brecht ou Tennessee Williams. A poesia e o romance proletários da Lekra (Lembaga Kebudayaan Rakyat, Instituto da Cultura Popular), a rigor, derivaram sua estética de alterações pontuais, decididas por seus membros, de tradições locais, e não da literatura do realismo socialista fomentada pela União Soviética. Ver Keith Foulcher, "Politics and Literature in Independent Indonesia: The View from the Left”, Southeast Asian Journal of Social Science, v. 15, n. 1 (1987), pp. 85, 95 e 100 n. 2.

9 Ibnu Wahyudi, “The Circumstances of Early Moderm Indonesian Literature”, International Area Studies Review, v. 1, n. 2 (1998), p. 115. 
moderna chegou ao sudeste asiático $)^{10}$ - seja por falta de interesse dos pós-graduandos em confrontarem convenções firmadas desde a instituição dos estudos orientais modernos, seja por uma simples indisponibilidade de edições de obras de tradições anteriores, fora do escopo do Balai Pustaka, o que impede a divulgação desses textos.

\section{A retórica do desenvolvimento colonial: sobre a fundação da editora Balai Pustaka (1917-1942)}

Questionar como Andries Teeuw chegou ao cânone moderno indonésio nos abre diversos caminhos de análise. Os juízos do acadêmico não serão tomados enquanto manifestações de seu gosto pessoal, mas como construtos ideológicos que impregnaram a orientalística holandesa desde sua gênese. De fato, a lógica de sua argumentação corrobora, nos mínimos detalhes, a política cultural fomentada pela metrópole holandesa a partir de 1901, conhecida como Ethische politiek. Tal projeto propôs-se como uma ampla reforma na administração colonial que visava promover o aculturamento - isto é, a ocidentalização - de uma pequena elite nascida nas Índias, que eventualmente se tornaria apta a intermediar relações entre a população nativo-camponesa e os regentes que respondiam diretamente à rainha Wilhelmina.

Como diferencial, aquela reforma originou-se no seio da burguesia liberal holandesa. Comparativamente, era o que havia de mais humanitário em termos de tecnologias de colonização. Em vez da boa vontade dos governantes, foi um romance o responsável por chamar a atenção do público leitor para os abusos de autoridade perpetrados com dinheiro público: Max Havelaar, of de Koffij-veilingen der Nederlandsche

10 Claudine Salmon listou 806 autores sino-indonésios em sua pesquisa, ao passo que A. Teeuw menciona apenas 184 escritores das supostas origens da modernidade literária do país até a geração de 1966. Ver Claudine Salmon, Literature in Malay by the Chinese of Indonesia: a Provisional Annotated Bibliography, Paris: Éditions de la Maison des Sciences de l'Homme, 1981, p. 10. 
Handelmaatschappy (1860), obra-prima de Eduard Douwes Dekker, vulgo Multatuli, que hoje é a obra literária holandesa mais celebrada fora de seu país de origem. Este "livro que matou o colonialismo"11 serviu de motor para a tão necessária reforma política colonial da virada do século, não só em função de seu brilhantismo, mas por sua recepção calorosa nos círculos de jornalistas.

Dekker, é importante frisar, foi um grande inovador da estética realista ao transformar o livro em instrumento de sacrifício pessoal por criticar nominalmente oficiais que faziam rodar a máquina imperial holandesa o autor perdeu um cargo promissor nas Índias e teve que se esconder na Alemanha pelo resto da vida - e apelar a seus leitores históricos para que também lessem o livro com o coração aberto ao sacrifício: "Claro, acharam a leitura [de meu livro] 'agradável' e não pensaram ou fingiram não entender - que não foi para isso que eu, na meia-idade, joguei no lixo uma carreira que prometia ser brilhante", conforme se lê em um apêndice da segunda edição holandesa. ${ }^{12}$ Isso foi uma aproximação inédita entre realidade social e expressão literária, mais radical do que se via mesmo nos textos dos iluministas mais sanguíneos - se os iluministas contavam com a boa vontade da comunidade letrada para que mudanças sociais viessem à tona, Dekker sabia que o processo de reforma das Índias Orientais seria mais complicado. O sistema de exploração da época, o cultuurstelsel, fora pautado como um todo na barbárie e deveria ser desmontado. Tendo isso em vista, alguns dos jornalistas que liam de Multatuli compraram a primeira passagem para as Índias Orientais para registrar, de perto, as arbitrariedades delineadas de forma tão convincente no romance, mandando de volta para casa relatos escandalosos sobre o regime de semiescravidão que a população nativa vivia em função da tirania da antiga aristocracia local e dos regentes holandeses.

11 A formulação é de Pramoedya Ananta Toer, “The book that killed colonialism”, The New York Times Magazine, Nova York, 18 abr. 1999, p. 112.

12 Multatuli, Max Havelaar, ou Os leilões de café da Companhia Holandesa de Comércio, Belo Horizonte: Âyiné, 2019, p. 569. 
O que fazer perante aquela crise administrativa tornou-se uma pauta a ser resolvida pela sociedade civil e, pela primeira vez na história do colonialismo, o palco das discussões foram os jornais. ${ }^{13}$ No melhor do espírito democrático, a própria rainha Wilhelmina mostrou-se interessada em ouvir as propostas de seus súditos para a crise; foi quando o editor Pieter Brooshooft, após enviar uma comitiva de repórteres às Índias, concluiu sua série de reportagens apelando para a implantação de um plano "ético" de controle dos nativos, uma vez que os povos polinésios, presos em um estágio infantil da evolução da espécie, necessitariam de assistência, não de opressão (as palavras são do próprio editor). ${ }^{14}$ Por conseguinte, o periódico holandês De Locomotief passou a publicar artigos de cunho etnográfico, explicando os modos de vida e mentalidade de diferentes povos nativos a fim de preparar uma ciência da gestão colonial mais empática e, afinal de contas, mais efetiva do que aquela praticada por espanhóis, portugueses, ingleses ou holandeses até então.

Este é um aspecto central: a iminência da reforma servia também à lógica da competição de impérios, em uma época na qual as configurações do jogo colonial mudavam. Um dos grandes players do mercado algodoeiro, os EUA, que enriqueceram desde sua independência às custas do trabalho escravo de negros sequestrados da África, estavam decidindo o fim da escravidão em uma longa guerra que desestabilizou sua economia. A Inglaterra, consequentemente, dependente do algodão do sul dos EUA para alimentar sua Revolução Industrial, se viu forçada a buscar matérias-primas na Índia e criar uma infraestrutura mínima em suas colônias asiáticas, que estavam praticamente abandonadas. ${ }^{15}$ Nesse contexto, o repórter Snouck Hurgronje

13 Merle Calvin Ricklefs, A History of Modern Indonesia since c. 1200, Houndmills: Palgrave, 2001, pp. 193-205.

14 Citado em Adrian Vickers, A History of Modern Indonesia, Cambridge: Cambridge University Press, 2005, p. 17.

15 Essa conjuntura foi, já na época, formulada como uma crise diplomática e no sistema colonial: ver Karl Marx, “Die Krise in England”, Die Presse, Viena, 6 nov. 1861; “Zur Baumwollkrise”, Die Presse, 2 fev. 1862. O último artigo menciona a participação das Índias Orientais no processo de crise mundial (Karl Marx e Friedrich Engels, Werke: Band 15, Berlim: Dietz Verlag, 1980, pp. 348 et seq. e pp. 461 et seq. Tradução brasileira 
destacou-se como o mais talentoso e melhor conhecedor das Índias Orientais, o mais apto a elaborar um plano que faria a Holanda sair na frente, digamos, na corrida internacional por mercados. As Índias, afinal, já tinham uma infraestrutura pronta; bastava modernizar seu sistema de exploração e manter uma população de setenta milhões de nativos sob controle uma tarefa crescentemente difícil para um país minúsculo como a Holanda, que, já em 1938, contava apenas com trinta mil soldados treinados a postos na colônia oriental. ${ }^{16} \mathrm{~A}$ única solução razoável era estabelecer o controle mediante uma missão pacificadora e integradora, apresentada por Hurgronje em termos de uma Teoria da Associação, cuja essência foi expressa como uma "elevação dos nativos a um nível superior de civilização de acordo com suas capacidades inatas". ${ }^{17} \mathrm{O}$ alvo de um governo colonial ético era confirmar se os nativos educados seriam de fato capazes de absorver a sabedoria ocidental de forma a aperfeiçoar seu "caráter interior".

Cinco anos mais tarde, inspirado pela proposta de Hurgronje, o poder imperial já enviava excedentes de agentes pagos para se instalarem na colônia com a tarefa de estudar idiomas locais e entender a cultura nativa. ${ }^{18} \mathrm{O}$ nome do novo cargo era, sugestivamente, conselheiro de assuntos nativos para o Governo das Índias Orientais, cuja função se juntaria à dos já existentes taalambtenaren. ${ }^{19}$ Um dos pioneiros no ofício foi Godard Arend Johannes

no volume: Karl Marx e Friedrich Engels, Escritos sobre a Guerra Civil Americana, Londrina: Aetia, 2020). As reformas holandesas, é claro, não se limitaram a essa questão específica de gestão colonial: uma grande porção do norte da Sumatra também foi comprada do sultanato de Aceh, uma Lei Agrária foi instituída e houve abertura para entidades privadas de exploração das Índias, tudo a fim de garantir o domínio holandês. O processo foi bem retratado em Kementian Pendidikan dan Kebudayaan, Sejarah Indonesia, pp. 53 et seq.

16 Estatísticas presentes em Elizabeth Fitzpatrick, "Balai Pustaka in the Dutch East Indies: Colonizing a Literature” in Sherry Simon e Paul St-Pierre (orgs.), Translating in the Postcolonial Era (Ottawa: University of Ottawa Press, 2000), p. 117.

17 Hurgronje citado em Vickers, A History of Modern Indonesia, p. 22.

18 Andries Teeuw, “The Impact of Balai Pustaka on Modern Indonesian Literature”, Bulletin of the School of Oriental and African Studies, v. 35, n. 1 (1972), p. 112.

19 Trata-se de funcionários encarregados do estudo de línguas das Índias, instalados ali já desde o século XIX para auxiliar na diplomacia metropolitana (ver Teeuw, “The Impact of Balai Pustaka on Modern Indonesian Literature”, p. 112). 
Hazeu, mais tarde professor de literatura javanesa na Universidade de Leiden. Como um dos poucos versados na literatura arcaica da região, as conclusões que enviava à coroa tiveram grande impacto no futuro das políticas culturais: “esta literatura [javanesa], e suas formas tradicionais, não são adequadas para as necessidades que viriam a surgir como consequência da introdução, em escala relativamente ampla, da educação moderna nas Índias a partir de 1906”. ${ }^{20}$ Um novo panorama cultural surgia - complementa Teeuw - e com ele uma nova classe de leitores potenciais, de forma que os livros tradicionais dos javaneses eram insuficientes para saciar suas necessidades.

Dinheiro público passou a manter o chamado Kantoor voor de Volkslectuur - Escritório em prol da literatura popular - que, para dar mostras de seu impulso integracionista, foi rebatizado em 1918, adotando a designação em malaio pela qual é mais conhecido, Balai Pustaka.

Figura 1

A rede de influências (literárias e institucionais) que possibilitou o surgimento do Kantoor voor de Volkslectuur / Balai Pustaka em 1917-1918 ${ }^{21}$

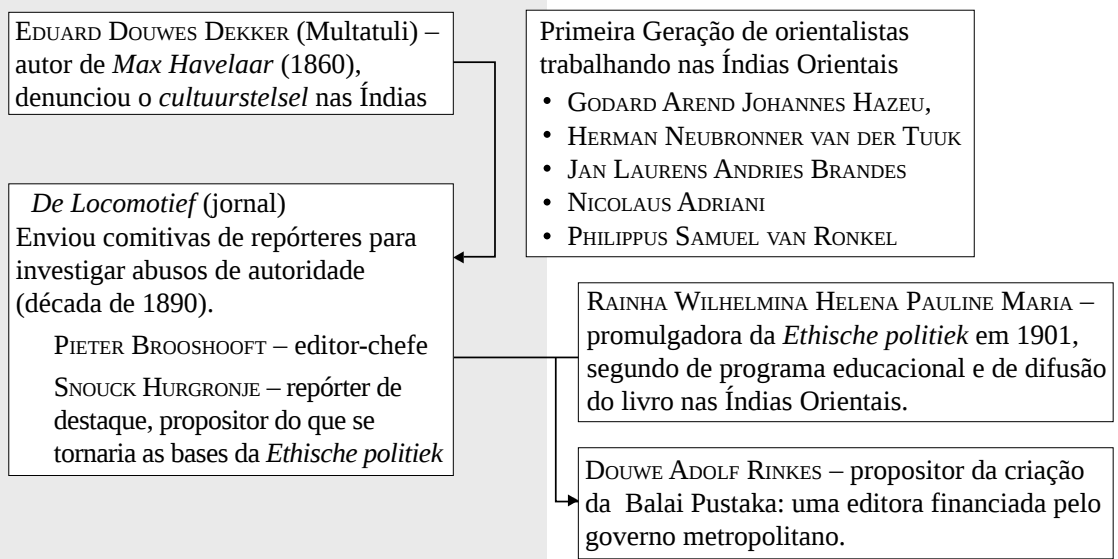

20 Teeuw, “The Impact of Balai Pustaka”, p. 112.

21 Elaborado pelo autor. 
Esta foi uma instituição bastante peculiar - funcionou praticamente como um ministério das literaturas e de sua difusão - que obteve resultados imediatos na região. Contando com um investimento maciço da máquina colonial, a Balai Pustaka passou a comissionar traduções de clássicos ocidentais e lançar livros de autores locais, contanto que se adaptassem às exigências de sua comissão de diretores (logo voltaremos a esse ponto). A grande mente detrás das inovações institucionais geradas pela Balai Pustaka foi Douwe Adolf Rinkes, que geriu a instituição buscando atender quatro funções:

1. Havia uma comissão editorial responsável por selecionar o material a ser publicado; nela concentravam-se tanto uma função técnica de preparação dos livros quanto uma função objurgatória: eram vetados livros que tratassem de política, dogma religioso, questões raciais e qualquer assunto interpretado como polêmico.

2. Havia uma seção administrativa (que prestava contas à Holanda, antes de tudo), coordenada pelo próprio Rinkes.

3. Havia uma seção de controle bibliotecário, responsável por criar um sistema de difusão de bibliotecas anexadas a escolas secundárias, além de bibliotecas móveis (as tais Taman pustaka, "jardins de literatura”), que viajavam pelas Î́ndias e, em certos anos, chegaram a registrar um montante de 2,5 milhões de empréstimos. Esse é um número altíssimo para um país majoritariamente analfabeto..$^{22}$

4. Por fim, havia um departamento de imprensa, cuja função era virtualmente ignorada até o estudo de Doris Jedamski de 1992, ${ }^{23}$ baseado em documentos imperiais encontrados no Algemeen Rijksarchief de Haia: o "Volkslectuur ajudou a delinear, promover

22 Ver estatísticas de empréstimos por título em Teeuw, “The Impact of Balai Pustaka on Modern Indonesian Literature”, pp. 114 et seq.

23 Doris Jedamski, “Balai Pustaka: a Colonial Wolf in Sheep’s Clothing”, Archipel, v. 44 (1992), p. 38. 
e impor padrões de interação social conforme se tornavam necessários por força das estruturas capitalistas predominantes.”24 Havia uma pauta para difundir desde medidas de higiene até rudimentos acerca de leis de trânsito, além de valores sobre o uso de dinheiro e de crédito. Com o emprego um tanto exagerado de publicidade dentro de livros e revistas, o comitê da Volkslectuur e sua editora Balai Pustaka "exerceram um papel importante de transmitir conceitos ocidentais de cognição, isto é, delineando e estabelecendo valores, modelos comportamentais e novas gamas de funções sociais”. ${ }^{25}$

Aquela era uma época em que o lucro constituía o único objeto de políticas coloniais; de um ponto de vista da gestão, isso tornava a máquina colonial inefetiva, instável e constantemente sujeita a rebeliões locais. Nesse sentido, Rinkes foi um visionário: como formula Fitzpatrick, ${ }^{26}$ controlar a literatura daquele povo seria o meio mais adequado de controlar suas aspirações, valores e ações. Como pupilo de Hurgronje, Rinkes transformou o impulso colonizador (que ainda não era concreto) dos jornalistas em política pública. Dessa vez, a literatura havia sido eleita como ferramenta primária de reeducação dos nativos.

\section{Resultados mistos da Balai Pustaka: o caso de Sitti Nurbaya (1922)}

Visamos o seguinte: enquanto nacionalistas continuam inoculando veneno nas mentes do povo por meio de peças teatrais e outras performances, a fim de inflamá-lo de raiva contra o governo, tenho o desejo de administrar um antídoto no formato de wayang [teatro de marionetes],

\footnotetext{
24 Jedamski, "Balai Pustaka”, p. 38.

25 Jedamski, “Balai Pustaka”, p. 23.

26 Fitzpatrick, "Balai Pustaka in the Dutch East Indies”, p. 119.
} 
de forma que as pessoas passarão a amar o governo (correspondência oficial de um bupati não identificado). ${ }^{27}$

Pesquisas iniciais da comissão editorial evidenciaram dois dados sobre seu público-alvo - aquelas eram comunidades majoritariamente iletradas, que durante sua história designaram uma casta de indivíduos para estudar e transmitir textos sagrados, e outra casta versada nas letras regionais e estrangeiras para propagar a cultura geral. O dalang javanês, por exemplo - mestre títere que controla os bonecos do teatro wayang - é, até hoje, simultaneamente um escolástico que teve de passar por um longo treinamento de suas artes e o responsável pela montagem das peças. Dele espera-se conhecimento adequado das tradições - em Java, por exemplo, esse conhecimento se pautou amplamente em variações de episódios da épica indiana Mahābhārata, “a grande fonte de inspiração para o teatro javanês, mas também o livro do qual qualquer javanês autêntico deriva sua moral e código social”. ${ }^{28} \mathrm{O}$ mesmo ocorre com a tradição épica do hikayat (lendas de heróis envolvendo um misto de personagens mitológicas e históricas) e com a transmissão de máximas de sabedoria mediante versos, como na poesia pantun - cada um desses gêneros pressupõe uma profissionalização distinta por parte do artista. Se a Balai Pustaka, em seus primórdios, quisesse impactar o público indonésio, devia publicar registros textuais propícios à transmissão oral ou mesmo realizar uma recitação dramática perante grandes grupos (pois já existia uma cultura autóctone do espetáculo). Ademais, o conteúdo desses livros, por mais moderno que fosse, não chamaria atenção caso não tivesse uma roupagem tradicional. ${ }^{29}$

O trabalho de um tradutor nativo de Sumatra, Muhammad Nur Sutan Iskander, foi particularmente importante neste ramo: Iskander

27 Citado por Jedamski, "Balai Pustaka”, p. 37 (grifos no original).

28 Teeuw, “The Impact of Balai Pustaka”, p. 113.

29 Fitzpatrick, "Balai Pustaka in the Dutch East Indies”, p. 119. 
traduziu Alexandre Dumas adaptando os cenários franceses a paragens conhecidas nas ilhas de Sumatra e Java, e as histórias de Sherlock Holmes de Arthur Conan Doyle aliando-as a convenções do gênero detetivesco já bastante famoso no arquipélago, pelo menos, desde 1850, que em jornais de cidades portuárias malaias se mesclava com notícias verídicas de assassinatos e grandes roubos. O projeto editorial se pautava em um princípio de adaptação, com o objetivo de expor o público nativo à sofisticação do romance de aventuras e grandes dilemas da literatura clássica europeia e dos EUA. ${ }^{30}$ Por outro lado, os grandes sucessos da Balai Pustaka foram adaptações de épicas sul-asiáticas antigas - em sua maioria material já recolhido por etnógrafos holandeses, traduzidos para o javanês moderno e, posteriormente, quando surgiu a necessidade de normatização da língua indonésia, para uma versão de malaio de Riau, variante linguística falada na região central de Sumatra, de onde vinha toda a equipe de tradutores em torno de Iskander. Ocorre então um acidente de percurso que constituiu, progressivamente, o impacto duradouro da Balai Pustaka - a versão do malaio estandardizada por seus editores, que mais tarde se tornou bahasa indonesia, calhou de ser a língua materna dos tradutores nativos que trabalhavam para a editora (todos naturais de Sumatra, membros da etnia minangkabau). Este acidente ajudou a estabelecer o idioma da unificação nacional, padronizado nos anos seguintes. Neste momento a editora oficial das Índias Holandesas desempenhou um papel de importância inegável na história do país independente. ${ }^{31}$

30 Para uma listagem de obras ocidentais traduzidas e os critérios de seleção editorial, ver Teeuw, “The Impact of Balai Pustaka on Modern Indonesian Literature”, p. 116; Jedamski, "Balai Pustaka”, pp. 25 et seq.; e Fitzpatrick, "Balai Pustaka in the Dutch East Indies”, pp. 119 et seq.

31 Ver Teeuw, “The Impact of Balai Pustaka on Modern Indonesian Literature”, p. 116. A estabilização do idioma bahasa indonesia gerou uma realidade peculiar ao país: boa parte dos autores indonésios atuais, embora escrevam na língua oficial, aprenderam-na como segunda ou terceira língua. 
O romance Sitti Nurbaya (Senhorita Nurbaya) (1922), ${ }^{32}$ de Marah Rusli, expressa bem os intentos ideológicos da editora indo-holandesa e suas estratégias iniciais de disseminação; na condição de romance escrito por um nativo, nele lemos o conflito entre valores ocidentais e tradições orientais persistentes, mas que destroem o futuro de jovens indonésios modernos. O texto se inicia com a descrição dos rituais costumeiros de um começo de namoro - os jovens Nurbaya e Samsulbara se reconhecem como amantes por uma simples questão de afinidade. ${ }^{33}$ Samsulbara, membro da pequena elite com acesso à educação da metrópole, se vê no dilema de pedir a moça em casamento ou esperar alguns anos até terminar seus estudos em Batávia e só então voltar para casa. ${ }^{34}$ Após uma separação dolorosa, a história de amor dos dois se transforma em uma espécie de Romeu e Julieta das Índias. Os pais de Nurbaya, afundados em dívidas, encontram a chance de liquidá-las seguindo um dispositivo social habitual em Sumatra: em troca da anulação das dívidas, a família entregaria a filha Nurbaya a seu credor, Datuk Meringgih - descrito como um velho abusivo. Naquele contexto, buscar uma renegociação da dívida por meios legais não livraria a família da pressão social de desonrar sua palavra como devedora. Toda a complicação do romance deriva daí: a força do código social nativo sobrepõe a possibilidade da felicidade do casal. Ao final das duzentas e tantas páginas que formam o romance, todos estão mortos: Nurbaya é vítima de seu marido, Meringgih e Samsulbara se enfrentam em um conflito final, falecendo em decorrência de seus ferimentos.

As marcas de ocidentalização transcendem a simples defesa de certos valores modernos - o individualismo, os dispositivos jurídicos para resolver o problema do endividamento, o casamento por opção, o amor romântico, o poder de uma mulher decidir seu próprio destino.

32 Utilizaremos a tradução de George A. Fowler (Marah Rusli, Sitti Nurbayya, Jacarta: Lontar, 2011) por falta de acesso a edições na língua original.

33 Rusli, Sitti Nurbaya, p. 6.

34 Rusli, Sitti Nurbaya, p. 47. 
Antes, os protagonistas, modernos e de espírito livre, são retratados como o que há de mais progressivo no romance, a ponto de se aproximarem dos holandeses até em sua aparência: Samsulbara, por exemplo, é descrito como "o jovem que poderia ser confundido com um holandês em seu caminho da escola para casa". ${ }^{35}$ Nurbaya, paralelamente, não perde a reverência respeitosa pelas vontades dos pais, de forma que não os confronta diretamente; mas ela é dotada de um senso de individualidade e valores liberais que engendram boa parte dos dilemas que ocorrem no texto. É como se unisse o melhor dos dois caráteres - nativo e moderno com holandês -, mas tivesse sua felicidade interrompida por força de um arranjo social injusto e retrógrado.

O retrato do antagonista do romance, Datuk Meringgih, é feito da forma mais desfavorável possível: constantemente somos lembrados de sua decrepitude, falta de modos e mesquinharia. É o símbolo perfeito do mercantilismo desenfreado, contrário ao suposto "capitalismo humanizado" da Ethische politiek holandesa; um homem de origens baixas que enriqueceu sem absorver o desenvolvimento anímico dos colonizadores endinheiradossua única lealdade, antes, está voltada a ganhos financeiros:

Europeu, chinês, árabe, indiano: não havia um único indivíduo em um cargo alto, de origem estrangeira ou local, que não tivesse relações estreitas com ele. E Datuk Meringgih cultivava tais contatos, sobretudo aqueles de altas posições. Será que tinha algum propósito em fazê-lo? Ou era por uma questão de gentileza? Teremos que esperar e ver. ${ }^{36}$

O dispositivo de antecipação da última frase, "teremos que esperar e ver”, amplamente utilizado nas tradições orais mencionadas, prevê um desenrolar muito evidente. Fitzpatrick mostra como o mesmo romance que se propõe produto da modernização termina por ser escrito fundamentalmente a partir da estrutura das épicas hikayat, com suas personagens

35 Rusli, Sitti Nurbaya, p. 1.

36 Rusli, Sitti Nurbaya, p. 7. 
divididas entre representantes óbvios do bem ou do mal e com um desenrolar inequívoco dos eventos, como se todos tivessem um destino pré-estabelecido e o romance servisse de grande espelho da ordenação eterna das coisas. ${ }^{37} \mathrm{O}$ fato de a ocidentalização dos heróis da narrativa ser inseparável das virtudes que os tornaram atrativos para seu público histórico é um fator de suma importância para pensarmos no romance inicial da Balai Pustaka: há nele uma transmissão muito evidente da imagem que os holandeses gostariam de passar para os nativos. Eles aparecem como mestres benevolentes, que não seriam facilmente substituídos por uma minúscula elite endinheirada de mercadores malaios locais (como Datuk Meringgih, o estereótipo do asiático enganador) - esta era uma gente sem modos, cultura ou com uma suposta ética empresarial daquele início de século XX. Mesmo cenas descontraídas em Sitti Nurbaya são enviesadas em defesa das virtudes da modernização holandesa: no terceiro capítulo do livro lemos como o jovem senhorio Samsulbara acorda às cinco da manhã para fazer um passeio nas montanhas locais, enquanto espera, impacientemente, pelo servo da família Arifin, velho e provinciano, reclamando por ter de fugir do hábito de acordar tarde. ${ }^{38}$ Se Arifin mostra a impossibilidade de a gente simples se atualizar em um mundo mais dinâmico, Samsulbara termina se gabando de sua pontualidade como indício da capacidade de se modernizar.

Algo semelhante ocorre em discussões sobre valores familiares. Uma discussão trivial do capítulo 2, de importância secundária dentro da fatura do texto, termina com a frase reveladora: "Estou mandando Samsu para a escola [holandesa]: da forma que vejo, um pai é obrigado a melhorar e promover seu filho”. ${ }^{39}$ Esses são alguns exemplos de um dispositivo de propaganda ideológica que preencheu os romances de nativos publicados pela Balai Pustaka - é justo dizer que a condição primária para que fossem publicados era satisfazer esse misto de função pedagógica e doutrinária que remontava ao programa colonial por trás da editora.

37 Fitzpatrick, "Balai Pustaka in the Dutch East Indies”, p. 122.

38 Rusli, Sitti Nurbaya, p. 24.

39 Rusli, Sitti Nurbaya, p. 13. 
Alguns textos são mais explícitos do que outros nesse aspecto. O romance posterior de Abdul Muis, Salah Asuran (1928), contém cenas que lembram roteiros de comerciais atuais de televisão: ${ }^{40} \mathrm{o}$ jovem Hanafi está em seu quarto refletindo sobre as desventuras que tem vivido. Ele sofre de uma forte dor de cabeça enquanto precisa achar uma solução para seus problemas. Fortuitamente, alguém bate à porta. $\mathrm{O}$ jovem atende e encontra um amigo holandês, um velho médico que traz às mãos um frasco de aspirinas. Ao encher um copo d'água e atirar nele uma pastilha, estende o copo ao jovem e diz: “tome uma aspirina, Han!” Não apenas mercadorias modernas, mas conhecimentos básicos sobre doenças venéreas, precauções de higiene e contra o abuso de drogas constituíram virtualmente toda a prosa de ficção publicada pela Balai Pustaka.

Quadro 1

Volumes originais de prosa publicados pela Balai Pustaka ${ }^{41}$

\begin{tabular}{|c|c|c|c|}
\hline Ano & Título & Tradução livre & Autor \\
\hline 1920 & Azab dan Sengsara & Dor e sofrimento & Merari Siregar \\
\hline 1922 & Sitti Nurbaya & Senhorita Nurbaya & Marah Rusli \\
\hline 1922 & $\begin{array}{c}\text { Habis Gelap Terbitlah } \\
\text { Terang }\end{array}$ & $\begin{array}{c}\text { Depois da escuridão } \\
\text { vem a luz }\end{array}$ & Raden Adjeng Kartini \\
\hline 1928 & Salah Asuran & Má criação & Abdul Muis \\
\hline 1928 & Salah Pilih & Má escolha & Nur Sultan Iskandar \\
\hline 1932 & Nasib & Destino & Habib St. Maharadja \\
\hline 1936 & Layar Terkembang & A vela se expande & Sutan Takdir Alisjahbana \\
\hline 1948 & $\begin{array}{l}\text { Dari Ave Maria ke Jalan } \\
\text { Lain ke Roma }\end{array}$ & $\begin{array}{l}\text { De Ave Maria a Um outro } \\
\text { caminho para Roma }\end{array}$ & Idrus \\
\hline 1949 & Atheis & Ateu & Achdiat Karta Mihardja \\
\hline
\end{tabular}

Mas nenhum produto foi mais bem promovido pela editora do que o pacote de valores civilizatórios europeus. Isso se deu por duas vias: uma explícita, de louvor direto aos modos de vida e novidades tecnológicas da

40 Jedamski, “Balai Pustaka”, p. 39.

41 Elaborado pelo autor. Além dos sete romances, o volume de Idrus é uma coletânea de contos; o texto de Habib St. Maharadja é uma autobiografia. 
Europa, e uma implícita, veiculada dentro do roteiro dos livros por meio de uma crítica da tradição, ou adat. O tradutor George A. Fowler define adat como um sistema "de crenças costumeiras e práticas não escritas" que determinam a organização social dos membros da etnia Minangkabau até hoje, influenciando mesmo as decisões em corte e na atual Sumatra republicana. ${ }^{42}$ Para que se tenha noção da força do adat como legislação invisível, não oficial, é ela que torna aquela sociedade matrilinear ainda hoje, em uma Indonésia majoritariamente muçulmana. Muitas vezes, o adat sobrepõem-se ao poder do Estado, e não por acaso os romances nativos que passaram pelo crivo da Balai Pustaka eram romances em que o adat era retratado como força a ser eliminada, ou ao menos subsumida sob os valores do mundo moderno. ${ }^{43}$

Não nos enganemos sobre a constituição de tais valores do mundo moderno: não eram valores emancipatórios, tampouco valores sob os quais os mestres holandeses levavam suas vidas, mas o contrário: esses valores nos levam à posição reformada em que gostariam de ver a nova elite de jovens indonésios educados, submetidos à hierarquia do império. Doris Jedamski, em seu estudo brilhante sobre a publicidade de revistas da época, dá um exemplo elucidativo da questão da emancipação feminina promovida nas nativas: as mesmas revistas repletas de artigos sobre a nova mulher das Índias, independente e confiante em si mesma, interessada em educar-se e revelar sua sensualidade para o marido, eram as revistas que desencorajavam a participação da mulher em movimentos políticos de independência, retratando-a como uma forma de dessexualização (a revista Doenia isteri, uma espécie de correlata da recém-surgida Marie Claire francesa, foi particularmente incisiva neste aspecto). ${ }^{44}$

O que surgiu como literatura um tanto doutrinária, consumida principalmente por uma classe de jovens letrados que partilhavam, pela primeira vez, da educação de holandeses e eurásios, engendrou,

\footnotetext{
42 Rusli, Sitti Nurbaya, p. xii.

43 Teeuw, Modern Indonesian Literature, pp. 54-55.

44 Jedamski, "Balai Pustaka”, p. 40.
} 
na geração seguinte, uma crise de consciência. Esta não foi uma crise gerada por força de qualquer conscientização anticolonial - de forma geral, a geração beneficiada pela Balai Pustaka aceitou a integração aos holandeses com bastante otimismo. ${ }^{45}$ Mesmo conscientes de que o monopólio editorial mantido com dinheiro da metrópole levaria editores independentes à falência, isso pareceu a muitos jovens intelectuais um sacrifício necessário. ${ }^{46}$ A crise na geração Balai Pustaka, antes, decorre da falência do projeto colonial. Mesmo a Ethische politiek teve resultados desastrosos; seu próprio idealizador, Snouck Hurgronje, mais tarde descobriu e denunciou os próprios administradores por desvios de verbas enviadas pela coroa para a educação dos nativos. Por fim, a ênfase da nova política educacional não expandiu significativamente oportunidades para crianças nativas, mas apenas consolidou uma hegemonia já existente, formada por antigas famílias de bupatis (herdeiros da aristocracia nativa) e administradores holandeses. ${ }^{47}$

Dessa forma, o período de admiração inquestionada de tudo o que fosse ocidental "estacou gradualmente quando os indonésios perceberam que aprender e absorver maneiras ocidentais não necessariamente os qualificava para serem admitidos na sociedade dos governantes e administradores coloniais”. ${ }^{48}$ A crise de consciência da geração imediatamente

45 Jedamski, “Balai Pustaka”, p. 36.

46 Jedamski, "Balai Pustaka”, p. 29.

47 Igualmente, em 1904, o editor Brooshooft retornou à Holanda em um estado de desespero, sentindo que sua luta pela justiça a favor dos nativos fora infrutífera. Seu último editorial tinha o título "Pamitan dengan orang sakit" (Adeus aos Doentes) e foi publicado no jornal Semarang, de 31 de dezembro de 1903. Por ter sido publicado em malaio, aquele era um alerta para os nativos, não uma tentativa de reformar a própria reforma colonial. Nem Brooshooft, nem Hurgronje pareciam mais nutrir esperanças de verem todo regente colonial se transformando, por força da sugestão, em uma versão das personagens virtuosas de Max Havelaar, "cuja bondade contribuiu - e não foi pouco - para o bom relacionamento entre os europeus e os chefes nativos” (Multatuli, Max Havelaar, p. 364). Poucos livros de história holandeses lembram que Política [colonial] ética é uma contradição em termos grosseira; seus próprios idealizadores já haviam concluído isso antes de morrer.

48 Tham Seong Chee, "The Social and Intellectual Ideas of Indonesian Writers, 1920-1942" in Tham Seong Chee, Essays on Literature and Society in Southeast Asia (Singapura: Singapore University Press, 1981), p. 97. 
posterior, portanto, seria engendrada por meio do encontro entre dois mundos irreconciliáveis. Tham Seong Chee chama a disposição de "second consciousness”, algo presente na obra de Armijn Pané nos anos 1940 e já antecipada por escritores publicados pela Balai Pustaka, como Abdul Muis e Achdiat K. Mihardja. Teria sido este descolamento da consciência, digamos, de um indonésio moderno, dividido entre os imperativos do adat e a modernização, o fator responsável por um amadurecimento da ideia de uma Indonésia autônoma. A partir de então, argumentam Teeuw, Chee e tantos outros, a intelectualidade indonésia, antes dependente de patronagem holandesa, começa a andar com as próprias pernas.

\section{Os dilemas do associacionismo: o caso de Salah Asuhan, de Abdul Muis (1928)}

O romance Má criação (Salah Asuhan) de Abdul Muis (1928), retrata uma crise na ideia do associacionismo, sugerindo o processo de ocidentalização de um nativo a partir de uma perspectiva tão negativa que, à primeira vista, parece incrível ter sido aceito para publicação na Balai Pustaka. Muis teve de submeter seu texto a uma série de revisões entre 1926 e 1928, a maioria delas envolvendo mitigar juízos desfavoráveis sobre o apetite sexual de mulheres europeias nas Índias. ${ }^{49}$

O protagonista é, mais uma vez, um jovem minangkabau, Hanafi, que recebeu a "má criação” prevista pelo título, sendo mandado para escolas holandesas que contribuíram para isolá-lo de sua comunidade mulçumana pautada pelas dinâmicas do adat (Muis, Salah Asuhan, p. 34). Hanafi convive quase exclusivamente com holandeses e eurásios e nutre esperanças de desposar a amiga Corrie de Bussée (filha de mãe minangkabau e pai francês). Embora lhe nutra afeto, a vergonha de ver a filha ao lado de um nativo leva o pai de Corrie a desencorajá-la da união

49 Keith Foulcher, "Biography, history and the Indonesian novel”, Bijdragen tot de Taal-, Land- en Volkenkunde, v. 161, n. 2-3 (2005), p. 249. 
(algo que ela expressa em uma carta presente na página 56 da edição referida). Na carta, Hanafi é relembrado do arranjo social da segregação e aconselhado, mesmo naquela época de crescente integração do elemento nativo, a não questionar o tabu da miscigenação. Desiludido pelas possibilidades de integração, ele volta para o seio de sua família e aceita um casamento por adat com sua prima, Rapiah. O casal mantém um relacionamento frio - Rapiah é destituída de qualquer cultura ocidental e não recebeu educação formal, tornando-se logo alvo de desprezo do marido. Quando ele é mordido por um cão com hidrofobia e se vê obrigado a receber tratamento médico na cidade de Batávia, casualmente reencontra seu antigo amor, Corrie. Eles iniciam um caso e decidem se casar contra todas as imposições sociais. Neste ponto surgem duas divergências centrais entre o casal: Hanafi, agora ligado a círculos da elite, consegue um status intermediário entre o nativo e o eurásio, podendo assumir um cargo em repartições públicas das Índias. Mesmo assim, é vítima constante do racismo de conhecidos de Corrie. Contudo, ele mesmo tem uma parcela de culpa no fracasso amoroso: Hanafi não se acostuma com o que julga como modos libertinos da esposa (que sai com amigos homens sem a presença do marido), e começa a tratá-la de forma abusiva. Abandonando-a mais uma vez, volta para casa e descobre, em seguida, que Corrie padeceu em um surto local de cólera. Voltando para sua esposa e família, em pouco tempo comete suicídio, mas não sem deixar uma carta em que pede desculpas à família e esposa por seus desvios de conduta. O pedido final de Hanafi é ser velado de acordo com o adat em um funeral mulçumano.

Este livro central da história da Balai Pustaka foi visto por Teeuw como um acidente de percurso com poucas consequências: "apesar de sua composição algo desarmônica, trata-se de um livro interessante em função de [...] seu tema, que se encontra mais ou menos fora do escopo habitual do romance do pré-guerra". ${ }^{50}$ Em uma reconsideração tardia de seus juízos, cinco anos mais tarde, Teeuw coloca o romance de Muis

50 Teeuw, Modern Indonesian Literature, p. 67. 
no rol dos romances de meados de 1930 que começaram a ensaiar uma mudança de temáticas e estilo na narrativa, ganhando a devida maturidade na geração seguinte, com os autores em torno da revista Pujangga Baru. ${ }^{51}$ O romance de Muis, no entanto, revela tensões dentro da própria ideia de associação indo-holandesa - tal tensão mostra que o associacionismo nasceu sob o signo da crise colonial, e não como solução para ela. ${ }^{52}$

A crise por trás do associacionismo é, antes de tudo, uma crise de caráter axiológico. Tivesse ou não boas intenções, a Ethische politiek compartilhou o problema do colonialismo como um todo: ele é uma forma de paternalismo de fundo racista que nega, de antemão, autoconsciência aos povos colonizados. A lógica por trás das políticas culturais da colonização europeia pode ser depreendida daquilo que Michael Hawkins recentemente chamou de "historicismo imperial":53 trata-se de uma ontologia com pretensões à universalidade, na qual o colonizador, tal qual um ser dotado de onisciência histórica, se aventura a encaixar culturas estrangeiras em uma escala temporal de desenvolvimentos do espírito humano. No caso da Indonésia multiétnica, esse processo se evidencia de modo particularmente claro: papuásios - com seus povoados beligerantes e de tendências canibais - foram relegados a um estágio primitivo da civilização; timorenses, por terem aceitado o cristianismo, ocupariam um estágio posterior. Javaneses, por sua vez, são herdeiros de reinos gloriosos

51 Teeuw, “The Impact of Balai Pustaka”, p. 120

52 Há diferentes níveis de abertura apresentados por associacionistas rem relação às influências internas: desde Takdir Alisjahbana e Hans Bague Jassin (certamente foram os mais afeitos ao louvor acrítico à ocidentalização) aos irmãos Sanusi e Armijn Pané (mais céticos perante a possibilidade de integração). O próprio Muis, como revelado em um estudo comparativo de sua carreira política e escrita literária, era um nativo contrário à miscigenação; apesar de ter escrito um romance aberto a interpretações dissidentes, seus contatos com a Balai Pustaka conheciam sua fama de arquiconservador. Segundo ele: "conhecimento ocidental ergue o povo nativo enquanto ele mantiver o posto que lhe é designado na ordem colonial" (Foulcher, "Biography, history and the Indonesian novel”, p. 266). O que os liga aos demais associacionistas, apesar das divergências, é a opção por se verem fora das lutas anticoloniais travadas por virtualmente todos os movimentos de massa na ativa então.

53 Michael C. Hawkins, Making Moros: Imperial Historicism and American Military Rule in the Philippines’ Muslim South, DeKalb: Northern Illinois University Press, 2013, p. 4. 
do passado, como Srivijaya e Majapahit, além de herdarem avanços técnicos de grandes sultanatos medievais; isso os colocaria em um estágio um pouco mais próximo do europeu na escala de desenvolvimentos humanos. E assim por diante. Esse parece um jogo infantil de classificação narcísica do colonizador europeu, mas é extremamente relevante em um estudo de ideologia colonial, uma vez que, a partir dele, foram escritas políticas públicas que definem até hoje Estado e cultura do sudeste asiático. Estabelecer um status evolucionário permitiria ao colonizador deduzir os meios mais adequados para possibilitar o desenvolvimento do indígena rumo ao estágio “ideal” de civilidade, isto é, o estágio europeu.

Nesse sentido, o tipo de historicismo em questão inaugurou uma novidade na história da cultura que ainda define, em grande medida, como classes educadas pensam as classes populares e sua cultura na Indonésia: nele “o tempo é mais fundamental que o espaço”. ${ }^{54}$ Isto é: mediante um sistema de hierarquia das identidades culturais, os indivíduos passam a carregar marcas de temporalidade que, a priori, derivam de sua etnia e origem: um papuásio e suas artes tribais são julgadas mais primitivos do que os ritmos do dangdut, a música popular dos javaneses. Em 1930, um jovem das Índias Orientais versado em livros e dilemas modernos, próprios da cidade grande, se diferenciava de seus conterrâneos e encontrava postos de trabalho com as elites holandesas pela primeira vez, graças à nova cultura de integração. Mas - voltemos ao caso de Muis - a própria realidade das dinâmicas sociais lhe negava uma associação verdadeira. $\mathrm{O}$ associacionismo não passava de um desejo natimorto de solidariedade entre os povos.

Boas motivações não importam na abordagem aqui visada há pilhas de livros dedicados a louvar o humanitarismo holandês, mas, para fins de análise, tomemos a Ethische politiek, apesar de sua roupagem progressista, como um conglomerado de convicções política amplas que afetaram tanto (1) a escolha de textos literários para serem publicados e formar um cânone mínimo indonésio (via editora Balai Pustaka), quanto

54 Hawkins, Making Moros, p. 8. 
(2) a narrativa criada e repetida por historiadores da literatura do que se chamou aqui de escola de Andries Teeuw. Por trás das ditas convicções políticas há a "crença de que a compreensão ocidental de modernização, de progresso e de civilização - tomada por universalmente válida deveria ser cultivada”. ${ }^{55}$ Nesse sentido, pensar a Ethische politiek e aquilo que dela decorre como sistema de crenças revela a estrutura fundamentalmente ideológica da historiografia literária escrita a partir do início do século XX. Podemos dizer que a própria versão da narrativa histórico-literária aqui analisada é associacionista.

Ou seja: o que nela parece ser um sintoma é parte do programa ideológico a que serve - em Teeuw, Aveling, Jassin e outros grandes orientalistas é difícil encontrar qualquer nome fora da tradição nacionalista liberal (a mesma que declarava transcender a política da colonização e abraçar o associacionismo) no rol de escritores relevantes. Um leitor desavisado tem a impressão de que setenta milhões de nativos liam e comentavam uma literatura coesiva, representativa da missão histórica das Índias na véspera de sua independência: seu caminho a guiava a uma reintegração harmônica com as antigas forças coloniais e com a grande mãe Holanda. ${ }^{56}$

Há, decerto, a tentação de atribuir essa seletividade excessiva a dificuldades próprias do labor histórico: resumir uma longa lista de manifestações literárias, sobretudo de um país tão plural, é algo difícil de fazer em poucas centenas de páginas. Todo empreendimento de ciências humanas surge de uma necessidade de reduzir a complexidade do mundo e explicar os fenômenos com base em tendências e antagonismos, em uma ordenação de causa e consequência - mas justamente porque a História é uma ciência, seus resultados devem ser criticados quando as interpretações dos fenômenos perdem sua autoridade, dando brecha a falsificações. Neste caso, a falsificação é a mesma que a Holanda contou para seus súditos de ultramar desde o século XIX. Quando esmiuçamos o repositório da dita corrente oficial da historiografia literária indo-holandesa, seus

55 Jedamski, “Balai Pustaka”, p. 24.

56 Foulcher, "Politics and Literature in Independent Indonesia”, p. 92. 
textos parecerem ter sido escritos com o objetivo de justificar a eficácia dos projetos coloniais - só depois eles lidam com os fatos.

O maior fato que se nega, por fim, deriva daquilo que já foi dito sobre a crise axiológica de Muis: a corrente orientalista de Teeuw se entretém com um erro de indicar que, caso a Ethische politiek tivesse sido bem executada, os jovens indonésios ainda estariam aprendendo holandês na escola e bebendo cerveja belga. O conceito de "segunda consciência” de Tham Seong Chee, referido anteriormente, é igualmente problemático: ainda que a crise colonial crie um impasse esquizofrênico no intelectual nativo de meados de 1930, ${ }^{57}$ assume-se que tudo acabou sendo necessário para a independência.

O caso indonésio exemplifica aquilo que foi a experiência comum de tantas sociedades [que] outrora [estiveram] sob domínio colonial. O contato com o Ocidente inicialmente abriu os olhos da comunidade indígena para seu próprio caráter retrógrado. Uma das manifestações deste contato foi a reação crítica de escritores aos seus próprios costumes, instituições e crenças [...] A aquisição de educação moderna teve, por fim, o efeito de desenvolver a consciência, o conferir de uma escolha ou alternativa no pensamento e na ação. Foi esse estágio no desenvolvimento da percepção intelectual onde se situava a confiança de que uma sociedade completamente nova poderia ser criada caso se trouxesse à luz as fraquezas e deficiências da sociedade nativa. ${ }^{58}$

Em outras palavras, o desdobramento daquilo que começou como uma crise termina por atestar a justiça do sistema colonial holandês, ainda que só a posteriori: é como se os holandeses, como tutores benevolentes, mesmo que oferecessem resistência, tivessem dado a chance ao indonésio de lutar por sua autonomia, cientes de que só assim um indivíduo se

57 Chee, “The Social and Intellectual Ideas of Indonesian Writers”, p. 101, situa o debate por "necessidade de autonomia” a partir de polêmicas acerca da ocidentalização presentes em revistas ligadas à Balai Pustaka (como a Pujangga Baru) de setembro de 1935 a junho de 1939.

58 Chee, “The Social and Intellectual Ideas of Indonesian Writers”, pp. 115-116. 
torna apto para o mundo moderno. A perversidade desse argumento e tudo o que ele oculta está por trás da dita "resistência” oferecida pelos colonizadores, antes de presentearem seus pupilos asiáticos com o dom da autonomia: a resistência se deu no formato de uma invasão de outro colonizador, o japonês (1942-1945), seguida de uma guerra de cinco anos (1945-1949) que contava, inclusive, com a dizimação da população inteira de homens de aldeias para que se transformassem em campos de estupro exclusivamente habitados por mulheres, para deleite dos soldados. ${ }^{59}$ Se a experiência colonial holandesa (assim como a portuguesa, japonesa, britânica, alemã e espanhola) tem algo a nos ensinar, é que barbárie e civilização - esta dádiva dada aos nativos como se fossem migalhas são, muitas vezes, duas faces da mesma moeda.

No que se refere diretamente à história da literatura, a resistência holandesa aos dissidentes se deu igualmente mediante a criação de um monopólio editorial e decorrente negação, a autores e autoras fora do eixo Sumatra-Java, de acesso a um suporte institucional - a partir de 1925, sobretudo, autores ligados a partidos independentistas estavam proibidos de ser publicados. ${ }^{60}$ Desta feita, os produtos culturais de uma enorme massa de dissidentes (muito mais numerosa do que a meia dúzia de escritores recorrentes da Balai Pustaka) tiveram de ser veiculados na clandestinidade, e só muito recentemente vêm sendo resgatados por pesquisadores em trabalho de campo na Indonésia. ${ }^{61}$ Mesmo para o público acadêmico

59 Ver Vickers, A History of Modern Indonesia, pp. 92 et seq.; Ricklefs, A History of Modern Indonesia since c. 1200, pp. 261 et seq.

60 Ver documentação em Keith Foulcher, "Moving Pictures: Western Marxism and Vernacular Literature in Colonial Indonesia” in Doris Jedamski (org.), Chewing over the West: Occidental Narratives in Non-Western Readings (Amsterdã: Rodopi, 2009), p. 69.

61 Ver Dipa Nusantara Aidit, Dengan sastra dan seni yan berkepribadian nacional mengabdi buruh tani dan prajurit, Jacarta: Pembaruan, 1964, em seu trabalho sobre literatura proletária da Lekra; Asmara, “Tradisi Baru”, sobre o teatro de rua e adaptações contemporâneas do wayang a partir da renovação da arte por W. S. Rendra; Razif Bahari, "Remembering History, W/Righting History: Piecing the Past in Pramoedya Ananta Toer's Buru Tetralogy”, Indonesia, n. 75 (2003), pp. 61-90, e Rosemarie Simon-Bärwinkel, Chrestomathie der modernen indonesischen Literatur, Leipzig: Veb Verlag Enzyklopädie, 1973, sobre a ficção particularmente indonésia do realismo socialista; Foulcher, "Politics and Literature in Independent Indonesia", pp. 83-103 e 
local, o conhecimento sobre esse material é bastante restrito, podendo ser absorvido somente como parte de atividades extracurriculares.

$\mathrm{O}$ grande diferencial entre a literatura contemporânea e aquela subsidiada pelo governo das Índias (que Takashi Shiraishi chamou de pergerakan) foi seu uso ambivalente de influências ocidentais. Para ela, o Ocidente não deixava de ser uma fonte de ideias, ideologias políticas e impulso para renovações da vida do homem e mulher comuns. Na contramão do pensamento associacionista, porém, o Ocidente foi apropriado pelo mundo indígena, e não o contrário. ${ }^{62} \mathrm{Em}$ vez da imagem higienizada do holandês como uma encarnação do progresso e sofisticação, havia um interesse de pensá-lo em chave mais realista e, quando necessário, não poupar retratos críticos nos quais ele e seu sistema de exploração econômica serviam de instrumentos do atraso para as comunidades locais. A literatura da pergerakan é uma das tendências dotadas de modernidade e relevância estética que ainda está sendo redescoberta e em breve causará uma mudança significativa nos centros de orientalística: diante dessa manifestação mais antiga de realismo literário, Mrázek chega a fazer uma releitura do que a Balai Pustaka representou para a literatura indonésia, segundo a qual ela seria, antes de um nascimento digno do nome, uma "aniquilação de [sua] imaginatividade radical". ${ }^{63}$

Talvez esta seja uma postura exagerada. A importância da Balai Pustaka não deve ser minimizada - por meio dela foram revelados escritores e escritoras talentosos (como Abdul Muis e a princesa Kartini) que, sem dúvida, merecem seu espaço no cânone das letras do Sudeste Asiático. Além disso, a opção pela variante falada em Riau, Sumatra, para fins de normatização de

Takashi Shiraishi, An Age in Motion: Popular Radicalism in Java 1912-1926, Ithaca; Londres: Cornell University Press, 1990 sobre o romance urbano da geração perkerakan; e, por fim, Salmon, Literature in Malay, sobre a literatura escrita por minorias étnicas chinesas e a importação do modernismo chinês antes da Balai Pustaka. Para acesso a textos comentados, o ensaio mais recente de Foulcher, "Moving Pictures “, de 2009, traz uma lista extensa de material resgatado em sua pesquisa, além de reproduzir trechos do texto até então dado por perdido de Solikson chamado O Despertar, ou A história de Surya, um homem de intelecto (1928) [Menbangunkan atau Hikajat Surya seorang intelekt], originalmente publicado no periódico Api.

62 Foulcher, “Moving Pictures”, p. 41.

63 Citado em Foulcher, "Moving Pictures”, p. 71 
uma língua da independência nacional, por só si é um atestado do impacto imenso da Balai Pustaka e sua equipe na história daquele país.

Em poucas literaturas podemos ver com tanta clareza quão impactantes podem ser as políticas de difusão cultural, tanto na produção literária quanto na construção da autoconsciência artística de uma comunidade, como no caso das Índias Orientais neerlandesas. Este é um impacto que reverberou, também, no mapeamento futuro dessa literatura, evidenciando a imensa responsabilidade que temos em nossas escolhas como historiadores e historiadoras. Se uma lição pode ser tirada de todo o caso que começou com um singelo "a literatura indonésia moderna nasceu por volta de 1920”, ela é: um historiador da literatura não escolhe obras que julga serem aptas ou não a corresponder a demandas estéticas características de dada época. O silêncio por parte da crítica é, em muitos casos, a condenação da obra, e afetará não só a lembrança de seu autor, como também sua sobrevida nos meios de circulação física do livro.

Assim, o trabalho do historiador literário parte de um princípio de triagem, como todo labor científico, apesar de a própria natureza de seu objeto de estudo ser inclusiva. Uma vez que manifestações literárias são cumulativas - pois são sintomas superestruturais de tensões e conflitos internos à própria sociedade - o discurso homogeneizante da "escola literária em vigência”, da “autêntica literatura nacional”, invariavelmente está servindo a uma visão míope dos fatos. Como vimos, a miopia da historiografia indonésia está em vias de ser corrigida com a ideia de que aquele povo tem uma tradição fértil, apesar da colonização europeia, não por causa dela.

Recebido em 16 mar. 2020

Aprovado em 9 out. 2020

doi: 10.9771/aa.v0i62.35873 
Este artigo parte de uma história das origens da literatura moderna indonésia que, por muito tempo, foi aceita como oficial: ela conta como os nativos das então chamadas Índias Orientais Neerlandesas desenvolveram sua expressão literária devido a políticas educacionais da coroa holandesa, sobretudo o pacote de reformas promulgado em 1901 conhecido como Ethische politiek. O novo código colonial não só injetou dinheiro público para difundir os saberes, como criou uma editora oficial da colônia, a Balai Pustaka, que dali em diante monitoraria o material literário "adequado" para a população local. Analisam-se as implicações futuras dessa medida (que terminou por monopolizar o mercado editorial indonésio e calar autores dissidentes) e o surgimento recente de releituras da história das origens da modernidade literária no país.

\section{Historiografia da literatura | Literatura indonésia | Balai Pustaka | Andries Teeuw | Pós-colonialismo}

\section{How Many Hands does it Take to Write History of Literature? The Politics of Theoretical Divergences in Indonesia}

This paper begins with a history of the origins of modern Indonesian literature, one that for a long time has been accepted as the official version: accordingly, natives of what was then called the Dutch East Indies developed their literary expression due to the educational policies of the Dutch crown, especially after the reform package promulgated in 1901 known as Ethische politiek. The new colonial code not only had injected public money in order to spread knowledge, but also created an official publishing house in the colony, the Balai Pustaka, which thitherto would have monitored the 'proper' literary material for the local population. We analyze the future implications of such a measure (one that ended up creating a monopoly over the Indonesian editorial market and stifling dissident authors), as well as the recent onset of reinterpretations of the history of origins of literary modernity in that country.

Historiography of literature | Indonesian literature | Balai Pustaka | Andries Teeuw |
Postcolonialism 